\title{
The ghrelin and leptin responses to short- term starvation vs a carbohydrate-free diet in men with type 2 diabetes; a controlled, cross-over design study
}

\author{
Frank Quentin Nuttall ${ }^{1,2 *}$, Rami Mahmoud Almokayyad ${ }^{1,2,3}$ and Mary Carol Gannon 1,2,4
}

\begin{abstract}
Background: We recently have reported the 24-hour glucose, insulin and glucagon responses to a 72 -hour fast compared to a 72-hour macronutrient-sufficient, carbohydrate-free diet in men with type 2 diabetes. The 72-hour time period was used because it is the time required for the major metabolic adjustments to a lack of food to be instituted. As part of that study, ghrelin and leptin responses were monitored.

Methods: Twenty-four-hour total ghrelin and overnight fasting leptin concentrations were determined in males with type 2 diabetes when ingesting a standard, mixed meal diet (control), followed by a carbohydrate-free diet for $72 \mathrm{~h}$ or were starved for $72 \mathrm{~h}$, using a crossover design.

Results: A rise in ghrelin concentration before and a decrease after meals was present when the standard diet was ingested. However, in contrast to literature reports in normal subjects, a circadian variation was not apparent. Meal related changes were absent with starvation. A carbohydrate-free diet resulted in a daylong decrease in ghrelin. It also resulted in a $19 \%$ decrease in the overnight fasting leptin concentration. Leptin was decreased $54 \%$ with total starvation.

Conclusion: Ingestion of a typical mixed-meal diet results in meal-related changes in ghrelin similar to those reported in normal subjects, although the circadian rhythm was not apparent. Except for the lack of meal-related changes, starvation did not change the concentration. A carbohydrate-free, high fat diet resulted in a daylong suppression of ghrelin. The leptin concentration was decreased by both the carbohydrate-free diet and starvation.
\end{abstract}

Trial registration: ClinicalTrials.gov Identifier: NCT01469104.

Keywords: Ghrelin, Leptin, Carbohydrate-free diet, Type 2 diabetes, Dietary carbohydrates, Dietary fats, 24-hour profile

\section{Background}

We recently have reported the 24-hour glucose, insulin and glucagon responses to a 72-hour fast compared to a 72-hour macronutrient-sufficient, no-carbohydrate diet in men with type 2 diabetes [1]. The 72-hour time

\footnotetext{
* Correspondence: nutta001@umn.edu

'Section of Endocrinology, Metabolism \& Nutrition, and the Metabolic Research Laboratory (111G), Minneapolis VA Health Care System, 1 Veterans Drive, Minneapolis, MN 55417, USA

${ }^{2}$ Department of Medicine, Division of Diabetes, Endocrinology and Metabolism, University of Minnesota, 516 Delaware Street, SE, MMC 101, Minneapolis, MN 55455, USA

Full list of author information is available at the end of the article
}

period was used because it is the time required for the major metabolic adjustments to a lack of food to be instituted [2,3]. It also is a time period over which a loss in non-water body mass is minimal [3]. Our overall objective was to compare the results when the metabolic fuel being oxidized is largely fat, with or without a deficiency of an exogenous fuel supply. In addition, dietary carbohydrate elimination has been reported to mimic, in many regards, the metabolic response to short-term starvation (fasting). A remarkable decrease in the 24-hour integrated glucose and insulin concentrations occurred (49 \% and $68 \%$, respectively). Approximately $70 \%$ of 
the glucose response and $72 \%$ of the insulin response to short-term starvation could be attributed to removal of carbohydrate from the diet.

As part of that study, ghrelin and leptin responses were monitored. The results are presented and discussed in the current report. We were particularly interested in determining these effectors since there is a paucity of data in the literature regarding their response to dietary manipulations in people with type 2 diabetes. Although not well characterized, ghrelin and leptin are considered to be important in fuel metabolism.

\section{Methods}

\section{Study aim, design and setting}

The aim of the study was to determine the effect of a carbohydrate-free (CHO-free) diet and starvation on the 24-hour profile of total ghrelin concentration in subjects with type 2 diabetes.

This was a crossover study design with a four-week washout period between study arms. On one occasion the subjects starved, on the other occasion they received a calorie-sufficient, $\mathrm{CHO}$-free diet for $72 \mathrm{~h}$. The order in which subjects were assigned to receive a $\mathrm{CHO}$-free diet or were starved was alternated. Each subject was provided with a standardized dinner (55\% carbohydrate, $15 \%$ protein, and $30 \%$ fat), based on $25 \mathrm{kcal} / \mathrm{kg}$ body weight, to be ingested at home at $1800 \mathrm{~h}$ the day before the admission day. After that, only water was allowed until admission to the Special Diagnostic \& Treatment
Unit (SDTU, similar to a Clinical Research Center) the next morning.

For the first $24 \mathrm{~h}$ of each study arm the subjects ingested a standard diet consisting of $55 \%$ carbohydrate, $30 \%$ fat, $15 \%$ protein. For the next $72 \mathrm{~h}$ they either starved, or ingested a $\mathrm{CHO}$-free diet consisting of $<3 \%$ carbohydrate, $15 \%$ protein, $85 \%$ fat. The $\mathrm{CHO}$-free diet contained the same amount of protein as the standard diet. Dietary fat replaced the carbohydrate.

On the day of admission, each subject reported to the SDTU at $0700 \mathrm{~h}$. An indwelling IV catheter was inserted on that day, and blood samples were obtained at 0730 , 0745 and $0800 \mathrm{~h}$ for baseline determinations. Subjects received the standard breakfast, lunch and dinner at 0800, 1200 and $1800 \mathrm{~h}$, respectively. Blood samples were obtained every $15 \mathrm{~min}$ after each meal for the first hour, every $30 \mathrm{~min}$ for the second and third hour and hourly after that until the next meal or until $0800 \mathrm{~h}$ of the next morning (Fig. 1).

On the second day, subjects were asked to starve for $72 \mathrm{~h}$, or were provided with the $\mathrm{CHO}$-free meals at $0800 \mathrm{~h}, 1200 \mathrm{~h}$ and $1800 \mathrm{~h}$ for $72 \mathrm{~h}$. The total food energy distribution was breakfast $32 \%$, lunch $40 \%$, dinner $28 \%$. The subjects consumed all of the food provided without difficulty.

Ingestion of water was encouraged. Black coffee, tea without sugar or cream, and calorie-free beverages were allowed. The subjects were confined to the SDTU and were under nearly constant surveillance. Activity was

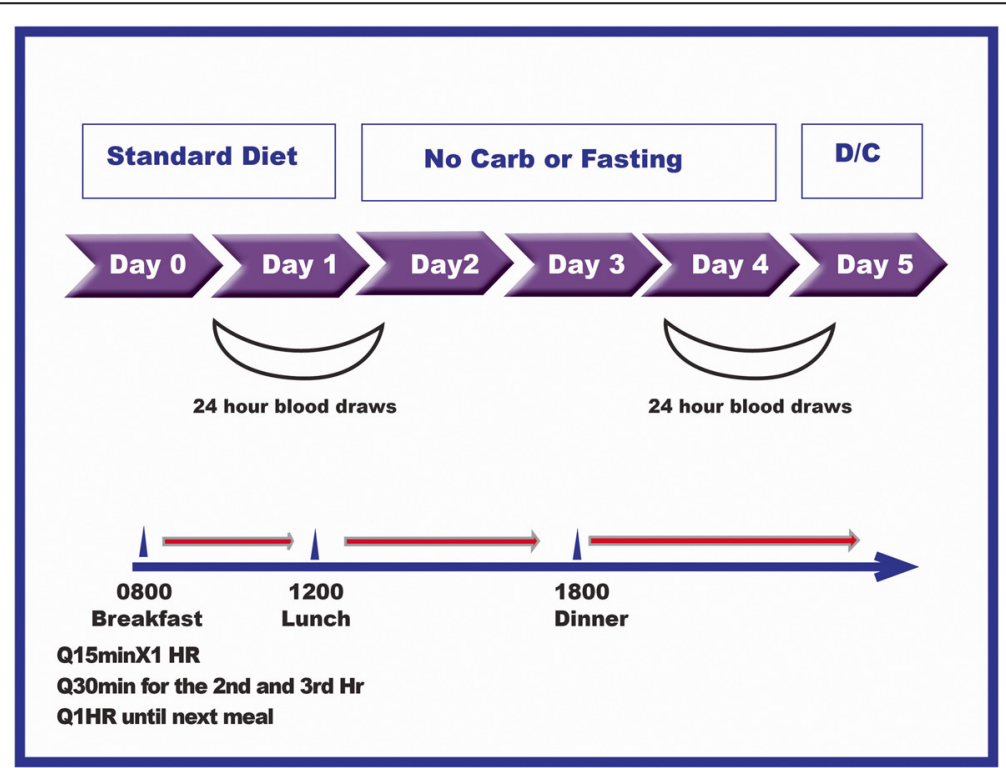

Fig. 1 Study Design. A standard diet consisting of $55 \%$ carbohydrate, $15 \%$ protein, and $30 \%$ fat was ingested for dinner at home at $1800 \mathrm{~h}$ before admission, and during day 1 in the SDTU. On one occasion during days 2-4 subjects starved, on the other occasion they ingested a carbohydrate-free diet. Meals were ingested at 0800, 1200 and $1800 \mathrm{~h}$. During two $24.5 \mathrm{~h}$ periods, from 0730 day 1 to 0800 day 2, and again from 0730 day 4 to 0800 day 5, blood was drawn a total of 42 times ( 3 baseline, every 15 min for $1 \mathrm{~h}$ after a mealtime, every 30 min for the 2nd and 3rd hours after a mealtime, and then every hour until the next mealtime 
limited to quiet diversions such as reading or watching TV. Smoking was not allowed during the study. Blood samples were obtained during last $24 \mathrm{~h}$ of the 72 -hour intervention, with the same time intervals as the first day. Thus, the data presented for the $\mathrm{CHO}$-free arm or starved arm represent the responses from the last 48 through 72 h of the study (Fig. 1).

With this design, each arm of the study had its own mixed meal control. Thus, we compared each of the $\mathrm{CHO}$-free and starvation data sets with their own respective standardized mixed meal control diets when analyzing the data.

\section{Participants}

Seven male subjects with untreated type 2 diabetes were studied in a clinical research unit (SDTU). All subjects met the American Diabetes Association criteria for the diagnosis of type 2 diabetes [4]. One subject was untreated; 3 subjects had been receiving metformin; 3 subjects had been receiving glipizide. These medications were discontinued for 24 or more days before the study, after obtaining approval by the subjects primary care providers. Thyroid, renal and liver function tests were normal. Subject characteristics have been published previously [1]. Briefly, the mean age was 60 years (range $49-72$ ); mean weight was $97 \pm 6 \mathrm{~kg}$ (range $81-130$ ); mean BMI $31 \pm 2 \mathrm{~kg} / \mathrm{m}^{2}$ (range $25-38)$.

The 24-hour ghrelin data were incomplete for one subject when ingesting the $\mathrm{CHO}$-free diet. Therefore those data, and his data when ingesting the corresponding control diet, were not used in the analysis of results, i.e. the results are for $n=6$. For the 6 subjects, the mean age was 60 years (range 49 - 72); mean weight was 100 $\pm 7 \mathrm{~kg}$ (range 88 - 130); mean BMI $31 \pm 2 \mathrm{~kg} / \mathrm{m}^{2}$ (range $25-38)$.

Written informed consent was obtained from all subjects, and the study was approved by the Department of Veterans Affairs Medical Center Internal Review Board (IRB).

\section{Assays}

Total ghrelin was assayed using radioimmunoassay (RIA) kits manufactured by Linco (St. Louis, MO); leptin was assayed using an enzyme-linked immunosorbent assay (ELISA) kit manufactured by $\mathrm{R} \& \mathrm{D}$ Systems (Minneapolis, MN).

\section{Area determination}

The net integrated 24-hour area responses were calculated using the overnight fasting concentration as baseline with a computer program based on the trapezoid rule [5].

\section{Statistics}

Statistics were determined by using paired Student's $t$ test with Prism Software (Graphpad Software, Inc. San Diego, CA) for the iMac computer (Apple, Cupertino, CA). A p-value less than 0.05 was the criterion for significance. Data are presented as the mean \pm SEM. Individual data points were not statistically evaluated for the 24-hour ghrelin profiles.

\section{Results \\ Total ghrelin \\ Carbohydrate (CHO)-free diet (Fig. 2)}

The overnight fasting total ghrelin concentrations at the beginning of the 24-hour collection period were $582 \pm$ 74 and $703 \pm 119 \mathrm{pg} / \mathrm{ml}$ for the control (top) and CHOfree days (bottom), respectively.

While ingesting the control diet, there was a decrease in ghrelin concentration after the breakfast meal. It then increased prior to the lunch meal and subsequently decreased, but the decrease was less than following the first meal. The concentration increased before the dinner meal and then decreased and remained stable overnight. Qualitatively, a circadian change in baseline was not apparent (Fig. 2, top).

When ingesting the $\mathrm{CHO}$-free diet the total ghrelin concentration decreased modestly until the midday meal after which it rapidly decreased further, reaching a nadir $6.5 \mathrm{~h}$ after breakfast. Except for a modest transient increase after the midday meal, it remained depressed and was stable until $21 \mathrm{~h}$, when it returned to the previous overnight fasting value (Fig. 2, bottom). That is, a negative circadian rhythm was observed.

\section{Net area responses}

When ingesting the control diet, the 24-hour total ghrelin net area response, using the overnight fasting value as baseline, was essentially zero $(286 \pm 765 \mathrm{pg} \mathrm{hr} /$ $\mathrm{ml})$, i.e. unchanged from baseline. However, it was considerably decreased when the subjects ingested the CHO-free diet $(-3666 \pm 1575 \mathrm{pg}$ hr/ml $)(P=0.04)$ (Fig. 2 bottom, insert).

\section{Short-term starvation (Fig. 3)}

The overnight fasting total ghrelin concentrations at the beginning of the 24-hour profile data collection period were $808 \pm 131$ and $703 \pm 100 \mathrm{pg} / \mathrm{ml}$ for the control (top) and starvation days (bottom), respectively $(n=7)$.

With starvation, the concentration remained essentially stable throughout the 24-hour period of study (Fig. 3, bottom). An intrinsic variation associated with meals was not present, that is the pre-post meal oscillations noted with the control diet were not observed. The control diet responses (Fig. 3 top) were similar to those obtained with the control diet for the $\mathrm{CHO}$-free arm 


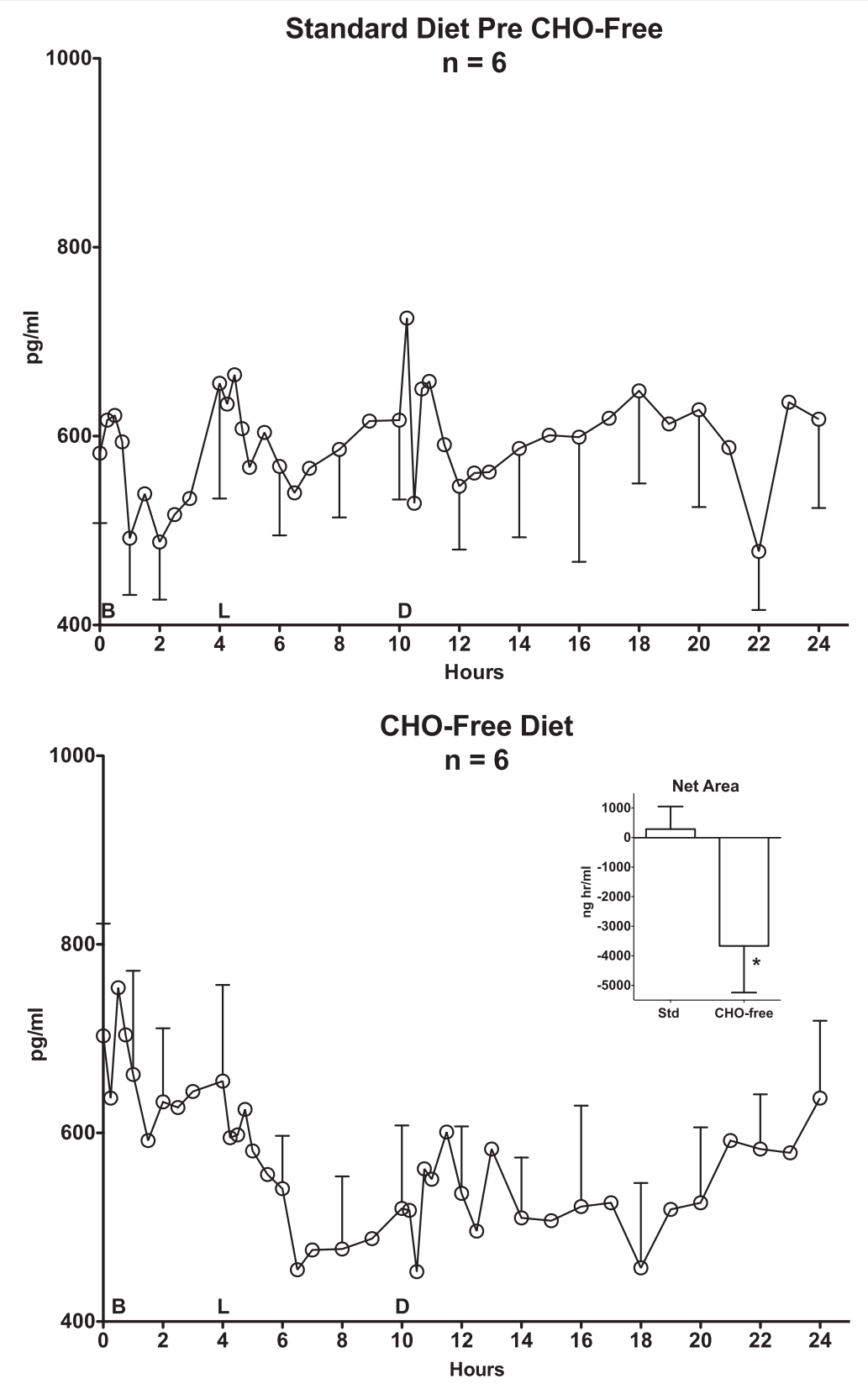

Fig. 2 Carbohydrate-Free Diet 24-hour Total Ghrelin Response. Twenty-four hour mean total ghrelin responses in 6 men with type 2 diabetes while ingesting a standard diet (top) and during the last $24 \mathrm{~h}$ of a 3 -day a carbohydrate-free diet (bottom). B, L, D on the x-axis indicate the time of breakfast, lunch, and dinner. Insert: Control (standard) Diet (286 $\pm 765 \mathrm{pg} \mathrm{hr} / \mathrm{ml})$ and the CHO-free Diet (-3666 $\pm 1575 \mathrm{pg} / \mathrm{hr} / \mathrm{ml}) 24 \mathrm{~h} \mathrm{Ghrelin}$ Net Areas. The differences in area responses are statistically significantly different $(P=0.04)$

(Fig. 2 top). Again, a circadian change was not apparent either with food ingestion or with starvation.

\section{Net area responses}

The 24-hour total ghrelin net area responses, using the overnight fasting values as baseline, were similar following the ingestion of the control diet $(118 \pm 1042 \mathrm{pg} h \mathrm{hr}$ $\mathrm{ml})$ or during the last $24 \mathrm{~h}$ of starvation $(-56 \pm$ $678 \mathrm{pg} \mathrm{hr} / \mathrm{ml})(P=0.89)$, (Fig. 3 bottom, insert).

In summary, when ingesting the standard diets, the pre and post meal oscillations were present. The net 24hour integrated ghrelin area values were unchanged when compared to the overnight fasting value. The area also was unchanged with starvation. Only for the CHOfree diet was it different, i.e. it was decreased. 

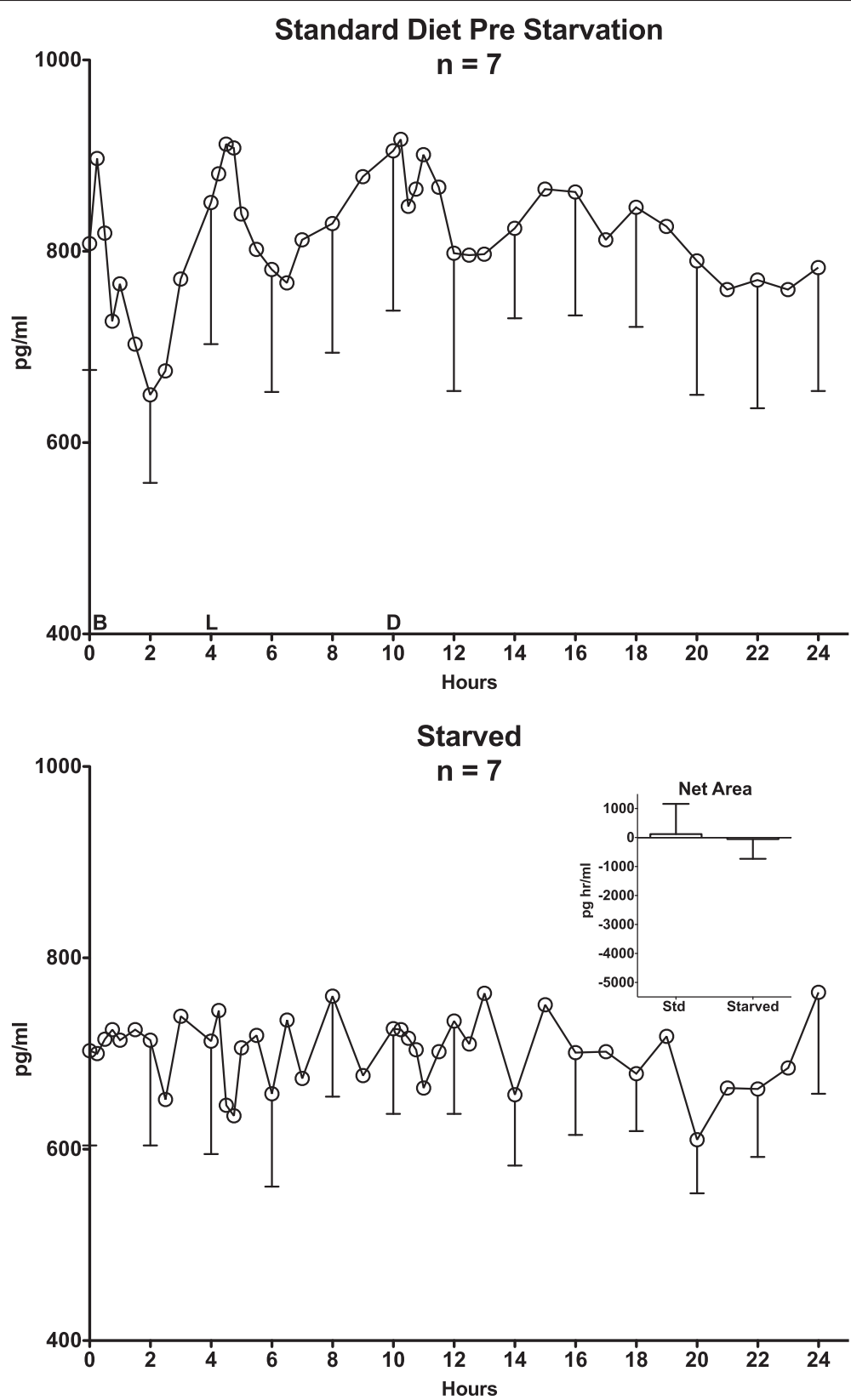

Fig. 3 Starvation 24-Hour Total Ghrelin and Insulin Responses. Twenty-four hour mean total ghrelin responses in 7 men with type 2 diabetes while ingesting a standard diet (top) and during the last $24 \mathrm{~h}$ of a 3-day fast (bottom). Insert: Control (standard) Diet (118 $\pm 1042 \mathrm{pg} \cdot \mathrm{hr} / \mathrm{ml})$ and Starvation $(-56 \pm 678 \mathrm{pg} \mathrm{hr} / \mathrm{ml}) 24 \mathrm{~h}$ Ghrelin Net Areas. The differences in area responses were not statistically different $(P=0.72)$

\section{Overnight fasting leptin concentrations (Table 1)}

Following ingestion of the CHO-free diet, the overnight fasting leptin concentration decreased from 10.0 to $8.1 \mathrm{ng} / \mathrm{ml}(P=0.01)$. With starvation it decreased from 11.4 to $5.3 \mathrm{ng} / \mathrm{ml}(P=0.04)$. Thus, with elimination of carbohydrate from the diet the decrease was $19 \%$. After the period of starvation it was decreased by $54 \%$.

Table 1 Leptin data $(n=7)$

\begin{tabular}{lcccc}
\hline Plasma/Serum & Control for CHO-Free & CHO-Free & Control for Starved & Starved \\
\hline Leptin $(\mathrm{ng} / \mathrm{ml})$ & $10.0 \pm 3.2$ & $8.1 \pm 2.7^{*}$ & $11.4 \pm 4.9$ & $5.3 \pm 1.8^{*}$
\end{tabular}




\section{Discussion \\ Ghrelin}

Several years ago, the 24 h circulating total ghrelin concentration was determined in normal subjects (9 females, 1 male) when typical (45\% CHO, $35 \%$ fat, $20 \%$ protein) mixed meals were ingested throughout the day [6]. The ghrelin concentration decreased episodically and rapidly after each meal and increased prior to the next meal. In addition, an underlying circadian rhythm was reported to be present with a nadir at $0900 \mathrm{~h}$ and an acrophase late at $0100 \mathrm{~h} \mathrm{[6].}$

The data therefore, suggested that rapid, food-induced changes in ghrelin could be regulating the dynamics of feeding and fasting throughout the day. The authors also commented that the circadian rhythm was similar to that of leptin, which also had been implicated in fuel regulation.

The same investigator group [7] later again determined the 24-hour total ghrelin profiles in a longer-term study in which ordinary foods were ingested. Normal subjects (16 females and 2 males) were provided a weight-stable diet (45\% CHO, $35 \%$ fat, $20 \%$ protein) for 2 weeks. The ghrelin 24-hr profile then was determined. Clearly defined decreases after meals, with rises before meals, were present. This again was on a background of rising concentrations during the day. That is, a well-defined and reproducible circadian rhythm was reported.

When the diet was changed to a high carbohydrate diet (65\% CHO, $15 \%$ fat, $20 \%$ protein) the profiles were similar [7]. The meal-related excursions were modestly greater when the high carbohydrate meals were ingested, but the $24 \mathrm{~h}$ integrated profile and area responses were reported to be unchanged. In the same study, a weight-loss regimen utilizing a high carbohydrate diet also did not result in a change in the 24-hr profiles or the integrated areas under the curves. The background circadian rhythm did not change regardless of the changes in diet.

In another study [8] the authors reported $24 \mathrm{~h}$ total ghrelin profiles in lean subjects and in obese subjects (8 females and 5 males) before and after a diet-induced weight loss. The subjects ingested regular mixed meals (55\% CHO, $30 \%$ fat, $15 \%$ protein). In obese subjects the profiles were similar, but the overnight fasting ghrelin concentration was lower, when compared to the lean subjects. Overall the meal-related changes were similar but somewhat less prominent [8].

In a previous 5-week study, we determined for the first time, the total 24-hour ghrelin profiles in subjects with untreated type 2 diabetes ingesting typical mixed meals (55\% CHO, $30 \%$ fat, $15 \%$ protein) [9]. The expected rise in ghrelin before meals and a post-meal decrease was present. The responses were similar to those reported in normal subjects, but not as well defined. In addition a circadian rhythm noted in normal subjects [7, 10] was not apparent [9]. The 24-hour background concentrations were stable and little changed from the initial fasting value. In the present study, the control diet was similar to that used in our previous study. As expected, the results were similar (Figs. 2 and 3).

Whether the lack of a background of rising concentrations during the day (circadian rhythm) in the present and previous study is unique to subjects with diabetes remains to be determined. It cannot be attributed merely to obesity [11]. Of interest, Norrelund et al. [12] reported that somatostatin strongly lowered ghrelin concentrations. Thus it may be playing a role in ghrelin regulation and may be modified in people with type 2 diabetes.

In our previous study [9] changing the macronutrient composition from $55 \% \mathrm{CHO}, 30 \%$ fat, $15 \%$ protein to $30 \% \mathrm{CHO}, 40 \%$ fat, and $30 \%$ protein had little effect on the ghrelin profiles. Thus, changes in macronutrient composition typically obtained in mixed meals had little effect on the meal-related changes in ghrelin response in people without [7] or with type 2 diabetes.

The effect of individual macronutrients remains somewhat unclear. In several single meal studies, carbohydrate (particularly glucose) ingestion resulted in a rapid decrease in ghrelin [13-19]. Thus dietary carbohydrates, if ingested independently or largely independently, and in sufficient amounts, can rapidly lower the ghrelin concentration in normal subjects. Ingested protein in one study did not result in a decrease in ghrelin [20]; in another it resulted in an increase [18]. Ingested lipids also had no effect on the ghrelin concentration in men and only had a very modest lowering effect in women [20]. Others reported it only weakly lowered it [16], had no effect [19], or actually increased it [18].

Later, Foster-Schubert et al. [10] reported that when ingested as $80 \%$ of the test macronutrient, dietary carbohydrate (absorbed glucose), protein or fats ingested in the morning as a liquid drink and in amounts representing $20 \%$ of estimated $24 \mathrm{~h}$ food energy requirement all resulted in a rapid and strong reduction in circulating total and acylated ghrelin. Protein was the most potent. Lipids were the least potent. Interestingly carbohydrate ingestion resulted in a biphasic response; the ghrelin concentration decreased rapidly followed by a rebound increase in concentration. In all cases a change in insulin concentration could not explain the results.

Others also have reported that introduction of these nutrients individually into the stomach and duodenum, all directly stimulated a decrease in circulating ghrelin concentration [21, 22]. This suggests major nutrient sensing in these organs. However, controlling for merely a change in osmolality was not included in the protocol. In rats, merely increasing the osmolality in the upper 
intestine was sufficient to signal a suppression in ghrelin concentration [23].

Thus, the relative role of the various macronutrients in suppression of the ghrelin concentration and their possible interaction in mixed meals remains unclear.

Recently we designed a study to determine, in young, normal subjects, if the degree of saturation of fatty acids in dietary fats (lard, olive oil, safflower oil) affected the metabolic response to ingested carbohydrate (potato) [24]. In that study both total and acylated ghrelin responses were determined and were similar. It was a single meal study. The responses were modest, but all types of ingested fats resulted in a decrease in ghrelin, whereas the response to carbohydrate was biphasic. Thus, when these typical foods were digested, the responses were similar to those noted by Foster-Schubert et al. [10] when nutrient-specific beverages were ingested. The response did not correlate inversely and temporally with the glucose or insulin responses.

Based on data obtained in subjects without diabetes by Foster-Schubert et al. [10], an increased dietary protein, as well as fat, relative to the carbohydrate content, might be expected to decrease the ghrelin meal response. This is particularly so if protein, as observed by them, is most potent in suppressing ghrelin production. However, as indicated previously, in subjects with type 2 diabetes ingesting mixed meals, a greater decrease in ghrelin concentration was not present when the protein content was doubled [9]. Thus, the role of dietary protein in regulating the ghrelin concentration remains unclear.

Somewhat surprisingly, in the present study, the $\mathrm{CHO}$-free, high fat diet resulted in a distinct, prolonged suppression of ghrelin throughout the day, i.e. the opposite of that expected based on the single meal studies in normal subjects $[10,13-17,25,26]$. The reason for this is not entirely clear. These data, and the data of a dietary fat-induced decrease in ghrelin obtained previously in our single meal study in young, normal people [24], do indicate that dietary fat can result in a lower total ghrelin concentration either in the presence or absence of dietary carbohydrate and with no change in protein content in people with or without diabetes.

It should be noted that in our 5-week study cited above [9], an increase in dietary fat content from $30 \%$ to $40 \%$ and a decrease in $\mathrm{CHO}$ from $55 \%$ to $30 \%$ also did not affect the 24-h ghrelin concentration profile. Likewise, others reported that small changes in the carbohydrate:fat ratio [7] or the protein:fat ratio [27] in normal subjects did not affect the 24-hour profile.

Overall, the sensitivity to changes in fat content needs to be determined in subjects with and without diabetes and with and without simultaneous changes in protein and carbohydrate independently and over an 18-24 h period. If similar data are obtained in people without diabetes, it suggests that dietary fat is a major inhibitor of ghrelin secretion in general, although an absence of carbohydrate may make it more apparent.

In this regard, it also would be of interest to determine if a high fat, $\mathrm{CHO}$-free diet-induced decrease in ghrelin also would inhibit appetite (food seeking). If so, would the effect be different in those with or without type 2 diabetes?

\section{Short-term starvation}

In normal subjects, others have reported short-term starvation did not increase the overnight fasting concentration [12] or the 24-hour integrated ghrelin concentrations [28]. Striking circadian rhythms were reported to be present with a decreasing concentration during the day and an increase during the night [11].

In the present study in subjects with type 2 diabetes, $48 \mathrm{~h}$ without food also was associated with little change in the overnight morning concentration but with a very stable 24-hour ghrelin profile thereafter. Thus the absence of metabolic fuel intake per se does not result in an increase in ghrelin concentration as noted after weight loss (reviewed in [29]).

\section{Leptin}

The overnight fasting leptin concentration is highly variable among people, but has been reported to be strongly associated with body fat mass [30,31]. It also is affected by age and gender. It is higher in women, even if the higher fat mass in women is considered. It becomes lower with aging [30].

The circulating leptin concentration also was reported to have a striking circadian rhythm with the lowest levels at midday and a maximum at $\sim 0200 \mathrm{~h}$ at night [32]. The rhythm is similar in young middle-aged normal men and women and in people with type 2 diabetes. This $24 \mathrm{~h}$ rhythm is entrained by the habitual meal timing of an individual [33]. However, in obese men and women, this occurred at a much higher leptin concentration [32, 34].

Studies in which the dietary macronutrient composition has been varied in weight-maintenance diets indicate little effect on the overnight fasting $[35,36]$ or $24 \mathrm{~h}$ leptin concentration [7, 27]. Leptin also does not respond acutely to meals $[7,27,32]$.

Leptin is sensitive to changes in total food energy intake. This response is rapid and not dependent on weight loss (Reviewed in [37]). After an overnight fast, a decrease in concentration was demonstrated as rapidly as $15 \mathrm{~h}$ without food and was maximal at $\sim 36 \mathrm{~h}$. However, during a glucose infusion, which merely restored the overnight fasting concentration to that prior to the fast, there was no change in concentration even though the subjects were still grossly food-energy deficient, i.e. the leptin concentration did not decrease [38]. 
Also, in a study of obese subjects in which the morning leptin concentration was monitored daily during a 4 day period without food, the leptin had decreased to a low, stable level within $24 \mathrm{~h}$. Interestingly, again infusion of a small amount of glucose, sufficient for a return of the glucose concentration to the level prior to the institution of the fast, resulted in a transient increase to that before food removal [31]. This occurred in the absence of a change in insulin concentration.

In the present study the $0800 \mathrm{~h}$ leptin had decreased $54 \%$ at the end of the period without food. This decrease is similar to those noted by others in normal subjects [31, 38, 39] (Reviewed in [37]).

To our knowledge, the effect of an essentially $\mathrm{CHO}$-free diet in people with or without type 2 diabetes has not been determined. The present data indicate that removing carbohydrate from a food energysufficient diet for $72 \mathrm{~h}$ results in a decrease in leptin concentration. The decrease was $35 \%$ as much as with $72 \mathrm{~h}$ without macronutrient ingestion. The decrease in $24 \mathrm{~h}$ integrated glucose concentration was $70 \%$ of that due to the absence of all food [1]. Thus, the current data in men with type 2 diabetes, as well as previous data in normal or obese individuals [31, 38, 40], suggest that the circulating glucose concentration [41] and/or maintenance of a defined overnight fasting glucose concentration can regulate the leptin concentration to food deprivation in general, either directly or perhaps indirectly [37].

Whether the current overnight fasting data reflect a 24-hour integrated concentration change remains to be determined. Quantitative 24-hour dose-response leptin data are necessary to fully assess the relationship of dietary glucose and/or maintenance of certain glucose concentrations on the leptin concentration dynamics.

\section{Conclusion}

Current literature data indicate that there remains considerable uncertainty, both in people without and with type 2 diabetes, regarding the quantitative ghrelin response to specific macronutrients and/or their combinations. In the present study the 24-hr ghrelin dynamic response to meals when ingesting a typical mixed diet was similar to that reported in subjects without diabetes. However, the typical circadian rhythm was not apparent. Short-term starvation did not change the $24 \mathrm{~h}$ integrated total ghrelin concentration, but the meal-related changes were absent. Removal of carbohydrate from the diet and replacement with fat resulted in a daylong decrease in ghrelin concentration.

The overnight fasting leptin concentration was decreased $25 \%$ by replacement of dietary carbohydrate with fat. It was decreased $55 \%$ with short-term starvation.
Abbreviations

$\mathrm{CHO}$, carbohydrate; IV, intravenous; SDTU, special diagnostic \& treatment unit

\section{Acknowledgements}

The authors thank the volunteers for participating in the study, the Staff of the Special Diagnostic and Treatment Unit, Heidi Hoover, R.D., M.S., Research Dietitian and Linda Hartich, M.T., for laboratory assistance.

\section{Funding}

Supported in part by funds from the Department of Veterans Affairs. This material is the result of work supported with resources and the use of facilities at the Minneapolis VA Health Care system.

The Department of Veterans Affairs had no involvement in study design, collection, analysis and interpretation of data, writing of the report or decision to submit the article for publication. The contents to not represent the views of the U.S. Department of Veterans Affairs or the United States Government.

\section{Availability of data and materials}

Following the current regulations of the US Government, final data sets underlying publications resulting from the research will not be shared outside the VA, except as required under the Freedom of Information Act (FOIA).

\section{Authors' contributions}

Dr. RMA was an Endocrine Fellow in training at the time this study was done. Dr. RMA applied for and obtained IRB approval for the study, recruited the subjects, obtained the blood specimens and contributed to the data analysis and preliminary draft of the manuscript. Drs. FQN and MCG obtained the funding, formulated and designed the study, performed the final analysis of the data and wrote the manuscript. All authors have read and agreed to the content of the manuscript and are accountable for all aspects of the accuracy and integrity of the data.

\section{Competing interests}

The authors declare that they have no competing interests.

\section{Ethics approval and consent to participate}

Written informed consent was obtained from all subjects, and the study was approved by the Department of Veterans Affairs Medical Center Internal Review Board (IRB).

\section{Individual person's data}

Not applicable.

\section{Author details}

${ }^{1}$ Section of Endocrinology, Metabolism \& Nutrition, and the Metabolic Research Laboratory $(111 \mathrm{G})$, Minneapolis VA Health Care System, 1 Veterans Drive, Minneapolis, MN 55417, USA. ${ }^{2}$ Department of Medicine, Division of Diabetes, Endocrinology and Metabolism, University of Minnesota, 516 Delaware Street, SE, MMC 101, Minneapolis, MN 55455, USA. ${ }^{3}$ Present address: Park Nicollet Health Care System, Minneapolis, MN, USA.

${ }^{4}$ Department of Food Science \& Nutrition, University of Minnesota, 1334 Eckles Avenue, St Paul, MN 55108, USA.

Received: 8 March 2016 Accepted: 13 July 2016

Published online: 22 July 2016

\section{References}

1. Nuttall FQ, Almokayyad RM, Gannon MC. Comparison of a carbohydratefree diet vs. Fasting on plasma glucose, insulin and glucagon in type 2 diabetes. Metabolism. 2015;64:253-62.

2. Cahill Jr GF, Herrera MG, Morgan AP, Soeldner JS, Steinke J, Levy PL, et al. Hormone-fuel interrelationships during fasting. J Clin Invest. 1966;45:1751-69.

3. Cahill Jr GF. Starvation in man. N Engl J Med. 1970;282:668-75.

4. American Diabetes A. Standards of medical care in diabetes-2010. Diabetes Care. 2010;33 Suppl 1:S11-61.

5. Gannon MC. A computer program to calculate the rate of appearance of glucose in the peripheral circulation following infusion of labeled glucose. Minneapolis: University of Minnesota, Patents and Licensing; 1991. 
6. Cummings DE, Purnell JQ, Frayo RS, Schmidova K, Wisse BE, Weigle DS. A preprandial rise in plasma ghrelin levels suggests a role in meal initiation in humans. Diabetes. 2001;50:1714-9.

7. Weigle DS, Cummings DE, Newby PD, Breen PA, Frayo RS, Matthys CC, et al. Roles of leptin and ghrelin in the loss of body weight caused by a low fat, high carbohydrate diet. J Clin Endocrinol Metab. 2003;88:1577-86.

8. Cummings DE, Weigle DS, Frayo RS, Breen PA, Ma MK, Dellinger EP, et al. Plasma ghrelin levels after diet-induced weight loss or gastric bypass surgery. N Engl J Med. 2002;346:1623-30.

9. Gannon MC, Nuttall FQ. Effect of a high-protein diet on ghrelin, growth hormone, and insulin-like growth factor-l and binding proteins 1 and 3 in subjects with type 2 diabetes mellitus. Metabolism. 2011;60:1300-11.

10. Foster-Schubert KE, Overduin J, Prudom CE, Liu J, Callahan HS, Gaylinn BD, et al. Acyl and total ghrelin are suppressed strongly by ingested proteins, weakly by lipids, and biphasically by carbohydrates. J Clin Endocrinol Metab. 2008;93:1971-9.

11. Espelund U, Hansen TK, Hojlund K, Beck-Nielsen H, Clausen JT, Hansen BS, et al. Fasting unmasks a strong inverse association between ghrelin and cortisol in serum: Studies in obese and normal-weight subjects. J Clin Endocrinol Metab. 2005;90:741-6.

12. Norrelund $\mathrm{H}$, Hansen TK, Orskov H, Hosoda H, Kojima M, Kangawa K, et al. Ghrelin immunoreactivity in human plasma is suppressed by somatostatin Clin Endocrinol (Oxf). 2002:57:539-46.

13. Blom WA, Stafleu A, de Graaf C, Kok FJ, Schaafsma G, Hendriks HF. Ghrelin response to carbohydrate-enriched breakfast is related to insulin. Am J Clin Nutr. 2005;81:367-75.

14. Nakagawa E, Nagaya N, Okumura H, Enomoto M, Oya H, Ono F, et al. Hyperglycaemia suppresses the secretion of ghrelin, a novel growthhormone-releasing peptide: Responses to the intravenous and oral administration of glucose. Clin Sci (Lond). 2002;103:325-8.

15. Nakai $Y$, Hosoda H, Nin K, Ooya C, Hayashi H, Akamizu T, et al. Plasma levels of active form of ghrelin during oral glucose tolerance test in patients with anorexia nervosa. Eur J Endocrinol. 2003;149:R1-3.

16. Monteleone P, Bencivenga R, Longobardi N, Serritella C, Maj M. Differential responses of circulating ghrelin to high-fat or high-carbohydrate meal in healthy women. J Clin Endocrinol Metab. 2003:88:5510-4.

17. Akhavan $\mathrm{T}$, Anderson $\mathrm{GH}$. Effects of glucose-to-fructose ratios in solutions on subjective satiety, food intake, and satiety hormones in young men. Am J Clin Nutr. 2007;86:1354-63.

18. Erdmann J, Topsch R, Lippl F, Gussmann P, Schusdziarra V. Postprandial response of plasma ghrelin levels to various test meals in relation to food intake, plasma insulin, and glucose. J Clin Endocrinol Metab. 2004;89:3048-54

19. Tentolouris N, Kokkinos A, Tsigos C, Kyriaki D, Doupis J, Raptis SA, et al. Differential effects of high-fat and high-carbohydrate content isoenergetic meals on plasma active ghrelin concentrations in lean and obese women. Horm Metab Res. 2004;36:559.

20. Greenman Y, Golani N, Gilad S, Yaron M, Limor R, Stern N. Ghrelin secretion is modulated in a nutrient- and gender-specific manner. Clin Endocrinol (Oxf). 2004;60:382-8

21. Ullrich SS, Otto B, Hutchison AT, Luscombe-Marsh ND, Horowitz M, FeinleBisset C. Comparative effects of intraduodenal protein and lipid on ghrelin peptide YY, and leptin release in healthy men. Am J Physiol Regul Integr Comp Physiol. 2015;308:R300-4.

22. Parker BA, Doran S, Wishart J, Horowitz M, Chapman IM. Effects of small intestinal and gastric glucose administration on the suppression of plasma ghrelin concentrations in healthy older men and women. Clin Endocrinol (Oxf). 2005;62:539-46.

23. Gelling RW, Overduin J, Morrison CD, Morton GJ, Frayo RS, Cummings DE, et al. Effect of uncontrolled diabetes on plasma ghrelin concentrations and ghrelin-induced feeding. Endocrinology. 2004;145:4575-82.

24. Radulescu A, Gannon MC, Nuttall FQ. The effect on glucagon, glucagon-like peptide-1, total and acyl-ghrelin of dietary fats ingested with and without potato. J Clin Endocrinol Metab. 2010;95:3385-91.

25. Mohlig M, Spranger J, Otto B, Ristow M, Tschop M, Pfeiffer AFH. Euglycemic hyperinsulinemia, but not lipid infusion, decreases circulating ghrelin levels in humans. J Endocrinol Invest. 2002;25:RC36-8.

26. Spranger J, Ristow M, Otto B, Heldwein W, Tschop M, Pfeiffer AF, et al. Postprandial decrease of human plasma ghrelin in the absence of insulin. J Endocrinol Invest. 2003;26:RC19-22.

27. Weigle DS, Breen PA, Matthys CC, Callahan HS, Meeuws KE, Burden VR, et al. A high-protein diet induces sustained reductions in appetite, ad libitum caloric intake, and body weight despite compensatory changes in diurnal plasma leptin and ghrelin concentrations. Am J Clin Nutr. 2005:82:41-8.

28. Chan JL, Bullen J, Lee JH, Yiannakouris N, Mantzoros CS. Ghrelin levels are not regulated by recombinant leptin administration and/or three days of fasting in healthy subjects. J Clin Endocrinol Metab. 2004;89:335-43.

29. Williams DL, Cummings DE. Regulation of ghrelin in physiologic and pathophysiologic states. J Nutr. 2005;135:1320-5.

30. Ostlund Jr RE, Yang JW, Klein S, Gingerich R. Relation between plasma leptin concentration and body fat, gender, diet, age, and metabolic covariates. J Clin Endocrinol Metab. 1996;81:3909-13.

31. Grinspoon SK, Askari H, Landt ML, Nathan DM, Schoenfeld DA, Hayden DL, et al. Effects of fasting and glucose infusion on basal and overnight leptin concentrations in normal-weight women. Am J Clin Nutr. 1997;66:1352-6.

32. Sinha MK, Ohannesian JP, Heiman ML, Kriauciunas A, Stephens TW, Magosin $S$, et al. Nocturnal rise of leptin in lean, obese, and non-insulin-dependent diabetes mellitus subjects. J Clin Invest. 1996;97:1344-7.

33. Schoeller DA, Cella LK, Sinha MK, Caro JF. Entrainment of the diurnal rhythm of plasma leptin to meal timing. J Clin Invest. 1997;100:1882-7.

34. Yildiz BO, Suchard MA, Wong ML, McCann SM, Licinio J. Alterations in the dynamics of circulating ghrelin, adiponectin, and leptin in human obesity. Proc Natl Acad Sci U S A. 2004;101:10434-9.

35. Schrauwen $P$, van Marken Lichtenbelt WD, Westerterp KR, Saris WH. Effect of diet composition on leptin concentration in lean subjects. Metabolism. 1997:46:420-4.

36. Havel PJ, Kasim-Karakas S, Mueller W, Johnson PR, Gingerich RL, Stern JS Relationship of plasma leptin to plasma insulin and adiposity in normal weight and overweight women: Effects of dietary fat content and sustained weight loss. J Clin Endocrinol Metab. 1996:81:4406-13.

37. Coleman RA, Herrmann TS. Nutritional regulation of leptin in humans. Diabetologia. 1999:42:639-46.

38. Boden G, Chen X, Mozzoli M, Ryan I. Effect of fasting on serum leptin in normal human subjects. J Clin Endocrinol Metab. 1996;81:3419-23.

39. Weigle DS, Duell PB, Connor WE, Steiner RA, Soules MR, Kuijper JL. Effect of fasting, refeeding, and dietary fat restriction on plasma leptin levels. J Clin Endocrinol Metab. 1997:82:561-5.

40. Jenkins AB, Markovic TP, Fleury A, Campbell LV. Carbohydrate intake and short-term regulation of leptin in humans. Diabetologia. 1997:40:348-51.

41. Herrmann TS, Bean ML, Black TM, Wang P, Coleman RA. High glycemic index carbohydrate diet alters the diurnal rhythm of leptin but not insulin concentrations. Exp Biol Med (Maywood). 2001;226:1037-44.

\section{Submit your next manuscript to BioMed Central and we will help you at every step:}

- We accept pre-submission inquiries

- Our selector tool helps you to find the most relevant journal

- We provide round the clock customer support

- Convenient online submission

- Thorough peer review

- Inclusion in PubMed and all major indexing services

- Maximum visibility for your research

Submit your manuscript at www.biomedcentral.com/submit
Biomed Central 